\title{
Training procedure and practice-test ratio in the acquisition and retention of a serial maze pattern
}

\author{
James R. Hawker \\ UNIVERSITY OF PITTSBURGH
}

\begin{abstract}
Abstraet
Forty Ss received a total of 30 practice and test trials on an electrical punchboard maze, and returned one week later to relearn the maze. The results showed that prompting and confirmation were equally effective in learning the maze pattern, but that confirmation resulted in a faster final performance speed, and led to significantly better retention.
\end{abstract}

\section{Problem}

A recent study investigating prompting and confirmation training procedures indicated that the two procedures were equally effective in learning a serial maze pattern (Hawker, 1964). While these results did not support those obtained with paired-associate material (e. g., Cook \& Spitzer, 1960), they were in general agreement with those obtained in a series of responseguidance (cf. prompting) studies of maze learning summarized by Carr (1930). The present study was designed to evaluate further the function of the two procedures in serial learning, and to see if varying the proportion of practice and test trials is a significant variable. Carr noted that response-guidance was most beneficial when a small amount was given early in training, and that it could become detrimental if continued too long. Similar results were obtained by Angell and Lumsdaine (1960) who found that a procedure involving prompting on only $75 \%$ of the trials was more effective than one giving prompting on $100 \%$ of the trials. In addition, information was wanted concerning the retention of the maze pattern when learned under the different conditions. None of the paired-associate studies has reported retention information, and Carr indicated that there was little relation between response-guidance and subsequent retention in maze learning.

\section{Method}

The Ss were 40 undergraduate students who participated as part of the course requirement in introductory psychology. A $2 \times 2$ factorial design was employed in which the two variables were: Training procedureprompting (P) or confirmation (C); and Practice-test ratio-series of two practice trials and one test trial $(2-1)$, or series of one practice trial and one test trial (1-1). The two variables in combination produced four experimental groups which can be labeled P1-1, C1-1, P2-1 and C2-1.

The apparatus was the electrical punchboard maze used in the earlier study, and the procedure was essentially the same as that previously described. During the practice trials, Ss under the confirmation procedure were required to trace the pathway by finding the correct response in each row by trial-and-error. Under the prompting procedure, however, Ss were shown the correct response at each point and traced the pathway without making errors. During the test trials, the procedure was identical for all Ss; they would trace the pathway through the maze without any prompting or any feedback as to their performance. The number of errors on the test trials and the time required to complete each test trial were recorded as the basic learning data.

All Ss received a total of 30 trials during the original learning session (Session I) and returned one week later and relearned the maze to a criterion of two consecutive errorless test trials (Session II).

\section{Results and Discussion}

The total number of errors during the original and relearning sessions is presented in Table 1 . Since the 2-1 and 1-1 conditions resulted in different numbers of test trials (10 and 15 respectively), a transformation of the scores was necessary to make them comparable for all groups. This transformation was made by dividing the total number of errors by the number of test trials, then multiplying by 10 to get rid of decimals. Analysis of the Session I error scores indicated no significant effects due to either of the variables or to the interaction, $\mathrm{F}<1.00$ in all cases. To see if there were any differential patterns in the error scores over trials, a second analysis was done by grouping the test trials into five blocks and performing a repeatedmeasures analysis of variance. Again, none of the main effects was significant.

Table 1. Number of errors and trials to criterion in original and relearning sessions.

\begin{tabular}{|c|c|c|c|c|c|}
\hline \multirow[b]{2}{*}{ Measure } & \multirow[b]{2}{*}{ Group } & \multicolumn{2}{|c|}{ Session I } & \multicolumn{2}{|c|}{ Session II } \\
\hline & & Mean & SD & Mean & $S D$ \\
\hline \multirow{4}{*}{$\begin{array}{l}\text { Total } \\
\text { Errors }\end{array}$} & $\mathrm{PI}-1$ & 20.9 & 11.28 & 5.9 & 5.76 \\
\hline & $\mathrm{Cl}-1$ & 20.9 & 10.07 & 3.2 & 3.49 \\
\hline & $\mathrm{P} 2-1$ & 24.4 & 15.80 & 6.0 & 8.55 \\
\hline & $c 2-1$ & 17.1 & $7 \cdot 52$ & 0.7 & 1.25 \\
\hline \multirow{4}{*}{$\begin{array}{l}\text { Trials to } \\
\text { Criterion }\end{array}$} & $\mathrm{PI}-\mathrm{I}$ & 15.6 & 7.41 & 11.0 & 6.34 \\
\hline & $\mathrm{Cl}-1$ & 18.4 & 5.48 & 5.6 & 3.75 \\
\hline & P2-1 & 23.7 & 5.56 & 11.4 & 9.78 \\
\hline & $C 2-1$ & 19.5 & 4.95 & 4.5 & 2.55 \\
\hline
\end{tabular}


A similar analysis was done on the Session I time scores and indicated no overall differences due to any of the variables. However, since it was found in the previous study that confirmation resulted in a faster final performance under a 2-1 schedule, $t$ tests were computed to compare groups $\mathrm{P} 2-1$ and $\mathrm{C} 2-1$. There were no differences between the groups on the first three blocks of trials, but the C2-1 group was faster on block IV, $\mathrm{t}(18)=2.35, \mathrm{p}<.05$, and on block $\mathrm{V}$, $\mathrm{t}(18)=2.23, \mathrm{p}<.05$. Similar comparisons between groups $\mathrm{P} 1-1$ and $\mathrm{C} 1-1$ produced no significant $t$ values.

Trials to criterion scores were obtained (Table 1 ) by taking the total number of trials preceding the first of two consecutive errorless test trials. For those Ss who did not reach criterion during Session I (approximately 10\%), a score of 30 was arbitrarily given. Training procedure had no reliable effect on trials to criterion, but Ss under the 1-1 conditions took significantly fewer trials to reach criterion than did those under the 2-1 conditions, $F(1,36)=6.03, p<.025$. There was a suggestive interaction between training procedure and practice-test ratio, but the obtained $\mathrm{F}(1,36)=3.49, \mathrm{p}>.05$, was not sufficiently large. To get more information about the effect of varying the proportion of practice and test trials, a series of $t$ tests was computed to make comparisons among the various groups. Since the test trials in the series are quite similar to confirmation trials (being "unprompted" trials), those groups receiving prompting under the 2-1 condition were receiving prompting on two-thirds or $67 \%$ of the trials, while those under the 1-1 condition were receiving prompting on one-half or $50 \%$ of the trials. Consequently, a difference in the performance of the P2-1 and P1-1 groups would indicate the effect of varying the amount of prompting received. While the two groups did not differ significantly in the mean number of errors, the $\mathrm{P} 1-1$ group did require significantly fewer trials to reach criterion in Session I than did the P2-1 group, $t(18)=2.76, \mathrm{p}<.02$. However, neither prompting group was superior to either of the confirmation groups. Since the practice and test trials are more similar under confirmation, one would not expect any difference between the $\mathrm{C} 1-1$ and $\mathrm{C} 2-1$ groups, and this is what the data indicated.

Finally, analysis of the relearning data (see Table 1) showed that confirmation led to superior retention of the maze pattern. The analysis of the Session II error data produced a significant training effect, $F(1,36)$ $=5.33, \mathrm{p}<.05$, as did the analysis of trials to criterion, $F(1,36)=9.68, p<.005$. Neither analysis indicated any reliable effects as a function of practice-test ratio. The two prompting groups were almost equal in both number of errors and trials to criterion, as were the two confirmation groups, which were decidedly superior to the prompting groups.

The present results, then, support the previous finding that prompting and confirmation are equally effective in learning a serial punchboard maze. In addition, both the error scores and the trials to criterion indicated that confirmation resulted in significantly better retention. While decreasing the amount of prompting facilitates acquisition of the maze pattern, it is still not more effective than a confirmation procedure. Moreover, the facilitative effect is lost when subsequent retention is measured.

\section{References}

ANGELL, D., \& LUMSDAINE, A. A. Prompted plus unprompted trials versus prompted trials alone in paired-associate learning. USAF Off. Scient. Res. tech. Note, 1960, No. 60-808. 19 p.

CARR, H. Teaching and learning. J. genet. Psychol., 1930, 37, 189-217.

COOK, J. O., \& SPITZER, M. E. Supplementary report: Prompting versus confirmation in paired-associate learning. J. exp. Psychol., 1960, 59, 275-276.

HAWKER, J. R. Supplementary report: Effects of prompting and confirmation in a serial learning task. J. exp. Psychol., 1964, 67, 99-101. 